\section{Discursos sobre o Estágio Supervisionado na formação de professores de Espanhol-LE}

Discourses about Supervised Internship in the training of Spanish-FL teachers

Rebeca Sales PEREIRA (UFC) rebeca_ufc@yahoo.com.br

Recebido em: 29 de maio de 2018. Aceito em: 27 de out. de 2018.

\section{0}

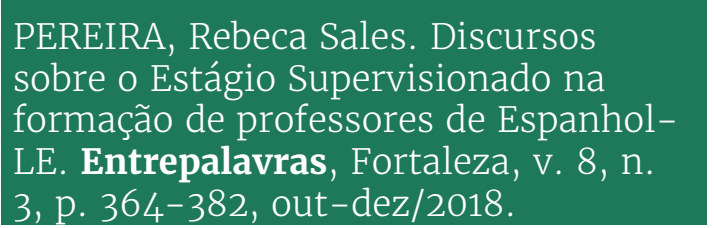

Resumo: O objetivo deste artigo é analisar identificações e representações nos discursos de futuros professores de Espanhol como língua estrangeira sobre suas experiências nos Estágios Supervisionados da Universidade Federal do Ceará e da Universidade Estadual do Ceará (2016-2018). Nosso aporte teórico tem base nos estudos de Tardif (2005) e Imbernón (2014) sobre Formação de Professores; Celani (2000, 2004) e Schnewly e Dolz (1999), sobre Ensino de Línguas; e Magalhães (2004) e Fairclough $(2002,2003)$ sobre Análise de Discurso Crítica. Os dados foram gerados a partir de entrevistas semi estruturadas e analisados mediante categorias textuais dos significados representacional e identificacional do discurso. Os resultados revelaram que o período do Estágio é considerado essencial para a formação docente, mas que há aspectos que urgem ser aprimorados: acompanhamento in loco do orientador, articulação entre teoria e prática específica de ensino de línguas e abordagem de aspectos sociais e de ideologia na formação do professor.

Palavras-chave: Formação Docente. Espanhol-LE. Análise de Discurso Crítica. 
Abstract: The aim of this article is to analyze identifications and representations in the discourses of future Spanish teachers as a foreign language about their experiences in the Supervised Internship of the Federal University of Ceará and the State University of Ceará (2016-2018). Our theoretical contribution is based on the studies of Tardif (2005) and Imbernón (2014) about Teachers Education; Celani (2000, 2004) and Schnewly and Dolz (1999) on Language Teaching; and Magalhães (2004) and Fairclough $(2002,2003)$, on Critical Discourse Analysis. The data were generated from semi-structured interviews and analyzed through textual categories of the representational and identificational meanings of discourse. The results revealed that the Internship period is considered essential for Teacher Education, but there are aspects that must to be improved: on-site advisor tutoring, articulation between specific theory and practice of language teaching and approach to social aspects and ideology in Teachers Education.

Keywords: Teacher Training. Spanish-FL. Critical Discourse Analysis.

\section{Introdução}

A formação em uma Licenciatura em Letras implica apreender conhecimentos e promover reflexões acerca de temas que vão desde teorias sobre os aspectos formais da língua a teorias de ensino e aprendizagem; visando a uma articulação entre tais princípios teóricos com a prática docente.

Em seu efetivo exercício profissional, o licenciado assume um novo lugar social (CERTEAU, 2008), que pode ser de reprodução ou de mudança diante de sua experiência como discente; e a sala de aula tornase não apenas seu lugar de atuação como pesquisador, mas também como regente, o que geralmente se inicia com o Estágio Supervisionado. É necessário, portanto, compreender a importância desse período de transição na formação docente, que pode representar maior conhecimento prático para sua futura atuação profissional ou ser mais uma razão de inquietações que não foram sanadas nas demais etapas do curso.

No que tange especificamente à formação de professores de Espanhol como língua estrangeira, não somente no Estágio, mas em outras disciplinas durante o curso, a universidade deve incluir variadas atividades que visem à plena formação do professor, preparando-o para aliar as teorias aprendidas à prática em diversos contextos. Além disso, esses professores também precisam considerar aspectos de interação professor-aluno, lidar com tempo de aula reduzido (geralmente 50 minutos por semana), indisciplina (em alguns contextos), imprevistos que alteram o planejamento da aula, disparidade de conhecimentos interculturais em relação aos alunos e ter um repertório didático atualizado (MATENCIO, 2001; COELHO, 2011). 
v. 8 (3)

$364-382$

out-dez

2018

A ampliação de Mestrados Profissionais em Letras no Brasil, nos últimos anos, demonstra interesse e incentivo na prática reflexiva do docente, que deve aliar seus papéis de regente e pesquisador, aprimorando sua formação, que deve ser contínua. Diante de tal complexidade de saberes requeridos, justificamos a importância deste artigo, que lança luz sobre os discursos desses profissionais em formação, para que possamos compreender esse processo, queé eminentemente mediado pela linguagem.

\section{Ensino de Línguas e Formação de Professores}

Assim como os contextos de ensino de línguas se apresentam heterogêneos, também o são os princípios teóricos. O ensino e a aprendizagem de línguas podem ser abordados sob diversas perspectivas teóricas, de acordo com sua classificação: materna ou não materna (segunda, estrangeira, adicional, de acolhimento, de herança etc.). Essas classificações tampouco têm consonância entre os pesquisadores (cf. ELLIS, 1994), portanto, destacamos nossa abordagem a partir da designação Língua Estrangeira (LE), pelo fato de nos referirmos ao Espanhol ensinado no Brasil, cuja língua materna é o Português e onde os estudantes, de maneira geral, não têm contato com a língua-alvo em interações comunicativas externas à aula de espanhol: nem dentro da escola, nem em outras práticas sociais ${ }^{1}$. Além disso, esse é o termo mais referido pelos participantes.

Na universidade, os formandos em Letras discutem diversas Teorias de aprendizagem de línguas, que vão desde o Behaviorismo (B. F. Skinner) ao Sociointeracionismo (L. Vygotsky), o que pode levá-los a se questionar se algumas teorias são incompatíveis com a prática. Esse aspecto torna relevante uma discussão sobre transposição didática, que é o ato de transformar um saber em objeto de ensino². Para Schnewly e Dolz (1999, p. 15), "não se pode ensinar sem que se faça a transposição", e o conhecimento sobre teorias contempladas pela Didática visa conferir habilidades ao formando nesse aspecto.

Sobre isso, De Jesus (2013, p. 10-11) afirma que um marco para o ensino de línguas foi "[...] o abandono de uma Didática específica para cada língua e o surgir de uma nova Didática: a Didática de Línguas (DL)", mas isso não ocorre em todas as instituições. Embora o curso de Letras tenha disciplinas que abordem questões específicas para a língua

\footnotetext{
${ }^{1}$ Salvo casos especiais, como famílias hispanófonas residentes no Brasil.

${ }^{2}$ Esse termo tem sido criticado pelos estudos contemporâneos acerca dos saberes pedagógicos, na área da Educação. Têm-se preferido os termos 'conhecimento pedagógico da matéria' ou 'saber da ação pedagógica' (GAUTHIER et al., 1998). No entanto, ainda é considerado válido nas teorias de Didática de Línguas.
} 
estrangeira, a disciplina de Didática continua sendo a mesma para todas as licenciaturas e não especificamente para línguas, muito menos para uma língua específica, como se comprova pela estrutura curricular das universidades investigadas e como está explicitado nas entrevistas.

O conhecimento dessas e de outras abordagens visa tornar o professor competente no momento de escolher qual delas acionar em determinado contexto de aprendizagem, embora não seja tão simples, tendo em vista questões que vão desde aspectos sociais de aprendizagem a questões administrativas e/ou institucionais que podem tolher as possibilidades de ação docente, o que será evidenciado na análise, pelas falas dos estagiários.

Adocência deve ter prioridade dentro de um curso de licenciatura, mas outras questões também são abordadas durante as aulas de ensino. Gimenez e Cristovão (2004) ressaltam a importância de que o profissional de Letras em formação possa não somente compreender como agir em sua prática, mas também seja capaz de refletir sobre ela; tornando-se assim, docente, pesquisador e avaliador de ensino (pois reflete sobre sua própria prática) e de aprendizagem (dos alunos). Obras como as organizadas por Prata et al. (2017) e Moreira et al. (2013), além da coletânea 'Dez anos da "Lei do Espanhol" (2005-2015)' (BARROS; COSTA; GALVÃO, 2016), denotam a importância de estudos sobre teoria e prática de ensino e aprendizagem de espanhol e sua relação com a formação de professores na contemporaneidade, por meio de um olhar interinstitucional.

No que tange à formação de professores, Pimenta e Lima (2004, p. 29) esclarecem que "considerar o Estágio como campo de conhecimento significa atribuir-lhe um estatuto epistemológico que supere sua tradicional redução à atividade prática instrumental". Sendo assim, o Estágio não pode ser reduzido a um treinamento, pois seu objetivo principal é instigar uma prática reflexiva como docente.

Tardif (2005, p. 178) postula que, para ensinar, o professor necessita de uma gama de saberes: ter domínio da teoria, de aspectos culturais, ter boa e convincente oratória e saber gerir uma sala em seus diversos aspectos administrativos e interpessoais; o que se aproxima de algumas teorias de ensino de línguas (Construtivista e Sociointeracionista, por exemplo). Imbernón (2014, p. 14) corrobora essa visão afirmando que o magistério não se reduz a uma simples transmissão de conhecimento, pois possui demandas contemporâneas que envolvem outras funções: "motivação, luta contra a exclusão social, participação, animação de grupos, relações com estruturas sociais, com a comunidade". Baseado nisso, justificamos a importância do que é discutido no próximo tópico. 
v. 8 (3)

$364-382$

out-dez

2018

\section{Análise de Discurso Crítica e Identidades Docentes}

Sendo a prática do professor de línguas um processo de contínua construção, é importante considerar a construção também de sua identidade por meio do discurso, de maneira crítica. Essa identidade é complexa e se transforma mediante suas experiências. Defendemos, neste trabalho, a importância de que o docente tenha uma prática autorreflexiva e esteja consciente de que o discurso é ingrediente importante para compreender questões que estão mais relacionadas a seu papel social como mestre, ao qual nos referiremos aqui como 'lugar social', termo de Certeau (2008). Conhecimentos sobre construção de identidades e representações podem auxiliá-lo na sua função, eminentemente mediada pela linguagem (como instrumento de comunicação e como objeto de ensino). A Análise de Discurso Crítica (ADC) reúne todos esses requisitos, motivo pelo qual a elegemos como teoria e método na análise dos discursos dos estagiários de Letras-Espanhol.

A ADC tem seis principais vertentes (cf. WODAK; MEYER, 2009), e este artigo está ancorado na perspectiva Dialético-Relacional, proposta pelo linguista britânico Norman Fairclough. A ADC de Fairclough se configura como área rica em conceitos que abrangem as áreas da Linguística e das Ciências Sociais. Para o presente trabalho, é importante ressaltar o conceito de discurso como um momento da prática social, também composta por outros momentos não discursivos. Dessa forma, o discurso é estudado por suas "combinações particulares de gêneros, discursos e estilos, que constituem o aspecto discursivo de redes de práticas sociais" (FAIRCLOUGH, 2003, p. 220).

A ADC investiga a linguagem quando envolve relações de poder e ideologia, sendo necessário compreender a conjuntura da prática e seu impacto nos discursos. A conjuntura ora analisada revela a importância do conceito de Modernidade Posterior (GIDDENS, 1991), pois consideramos o ensino de Espanhol no Brasil como sendo mediado por questões governamentais de desvalorização profissional que são citadas nas falas dos estagiários, como a revogação da lei 11.161, de 2005, que previa a implementação do Espanhol como língua estrangeira moderna obrigatória no currículo do Ensino Médio (a lei nº 13.415/2017 tornou-a opcional).

As identidades desses professores se viram abaladas diante da negativa do governo de sua relevância profissional na educação de jovens brasileiros. O curso de Letras-Espanhol (noturno) da UFC, por exemplo, teve sua criação impulsionada pela referida lei, diante de 
uma nova demanda que se criava naquele momento e que, por motivos relacionados ao Novo Capitalismo, foi desestimulada. Para Fairclough (2002), essa forma de economia se caracteriza por discursos de flexibilidade, rapidez de soluções e constantes mudanças em estruturas sociais; havendo uma 'comoditização' das semioses, o que se comprova com a rápida mudança da lei e a designação da língua inglesa como única obrigatória, por motivos políticos e comerciais.

Com base nisso, o próximo conceito da ADC caro a este trabalho é o de ideologia. Como a Teoria Social de Fairclough (2001) tem a mudança discursiva como primeiro passo para uma efetiva mudança social na luta contra discursos de ideologia hegemônica, o conhecimento dos atores sociais sobre aspectos ideológicos é relevante em suas tomadas de decisão.

Fairclough (2003) propõe um enfoque da análise textual em pesquisas sociais, ao propor o método de Análise de Discurso Textualmente Orientada (ADTO), baseada em uma reformulação das metafunções, propostas por Michael Halliday para a Gramática da Linguística Sistêmico-Funcional (LSF), em três Significados do Discurso, que possuem relação dialética (sem hierarquia). A ADC tem como foco, portanto, a "análise detalhada dos textos como janelas a iluminarem as práticas sociais" (MAGALHÃES, 2004, p. 5).

Após a geração dos dados, pudemos apreender as categorias relevantes no corpus e, portanto, nos deteremos na explicação breve apenas de tais categorias. A modalidade é uma categoria estudada por meio de várias abordagens ${ }^{3}$, mas, na $\mathrm{ADC}$, é fonte de análise de expressões avaliativas de valor (em termos do que é ou não desejável) e de afeto. A modalidade pode ser expressa textualmente por meio de verbos e advérbios modais, considerados modalizadores canônicos, mas também pode ser realizada por meio de adjetivos, substantivos, algumas orações ou expressões com sentido modalizador, além da entonação de fala. O uso de determinado modalizador em dado contexto proporcionará baixo ou alto comprometimento avaliativo dos atores sociais (FAIRCLOUGH, 2003). Conduziremos a análise com base nas categorizações de modalidade como epistêmica (nível das possibilidades) e deôntica (nível das obrigações), considerando todas as possibilidades de modalizadores textuais não canônicos: asseveradores (reforço do comprometimento com o que é dito) e atenuantes (diminuição do comprometimento com o que é dito).

3 Schlee (2011, p. 70) apresenta a discussão de vários autores acerca das denominações de modalidade, partindo de sua relação histórica com a Lógica. 
V. 8 (3)

$364-382$

out-dez

2018

A escolha lexical e as metáforas também são categorias do significado identificacional do discurso que se mostraram relevantes no corpus ora analisado, revelando posicionamentos ideológicos. Elas, além de serem empregadas pelos atores sociais em construções de imagens de si (identificações), são fontes importantes para a representação de atores sociais por meio do discurso. Fairclough (1995, p. 221) afirma que:

analistas do discurso têm um papel importante na formação de educadores/as críticos/as preparados para atuar em programas de consciência linguística crítica - programas que buscam desenvolver a capacidade das pessoas para a crítica linguística, incluindo capacidades de análise reflexiva do próprio processo educativo (FAIRCLOUGH, 1995, p. 221).

Defendemos, portanto, uma formação crítico-reflexiva, que considere questões de poder, como hegemonia e ideologia, além de questões identitárias que auxiliem na prática docente.

\section{Metodologia}

Para constituir o corpus deste artigo, realizamos entrevistas semiestruturadas com seis alunos matriculados em disciplinas de estágios de docência (observação e regência) da Universidade Federal do Ceará e da Universidade Estadual do Ceará, nos períodos de 2016.1 a 2018.1. Todos os participantes assinaram um Termo de Consentimento Livre e Esclarecido, autorizando a análise de dados.

Após as entrevistas, estas foram transcritas mediante as seguintes convenções adotadas (MAGALHÃES, 2000, p. 15): interrupções do fluxo de fala (/), pausas (...), ênfase de fala (letras em caixa alta) e repetições de palavras (hífen entre elas). Todos os nomes dos participantes foram preservados por pseudônimos: os estudantes da Universidade Estadual do Ceará são João e Helena, e os estudantes da Universidade Federal do Ceará são Viviane, Carlos, Lucas e Felipe.

A análise foi feita com base no método de Análise de Discurso Textualmente Orientada (ADTO), proposto pela Análise de Discurso Crítica, mediante as categorias textuais dos significados identificacional e representacional do discurso. 


\section{Estágio Supervisionado em cena}

A análise está delineada considerando que o Estágio Supervisionado é um processo composto por vários aspectos que impactam a formação do docente e sua visão de carreira profissional. Os entrevistados relataram que, antes de cursar o Estágio, faziam representações sobre esse processo a partir de falas de colegas que já haviam tido essa experiência. Algumas dessas representações são apresentadas nos seguintes trechos:

Helena: eu achei que ele iria me amadurecer MAIS né?[...] porém, eu vi que na verdade o estágio, ele é o seguinte[...] se você já tem vivência da área, é o que você vai levar, NÃO É o que você vai aprender na faculdade.

A escolha de Helena pelo vocábulo amadurecer denota sua representação do estágio como processo essencial em sua formação, mas não o único, já que vem anteposto ao advérbio de intensidade mais, aqui funcionando como asseverador do verbo. A estagiária é categórica (não usa modalizadores) quando se refere à mudança de pensamento sobre o estágio, após cursá-lo, valorizando unicamente a vivência na área (a oração adversativa iniciada com porém, revela a avaliação categórica de Helena sobre a importância do estágio em sua formação). Seu grau de comprometimento avaliativo é alto, e ela demonstra um pensamento de que o estágio não é condição sine qua non para seu desenvolvimento profissional. Os demais estagiários também o representam como um período que lhes suscitou mudança de crenças, mas, distintamente de Helena, suas representações se tornaram positivas:

João: [...] eu-eu pensava que era algo mais engessado, mais complicado, de você....NÃO SEI! Pelo que todo mundo fala pela rádio corredor, não era algo que ia acrescentar tanto, era mais uma coisa pra poder encher linguiça, assim, não sei.

Felipe5: [...] nossos colegas que já têm a experiência e ficam falando, a gente até um pouco que se assusta. Então, esse PRECONCEITO que a gente tem no início é um pouco

\footnotetext{
4 Quando as palavras ou expressões forem reproduzidas na análise exatamente como foram ditas na entrevista, serão grifadas em itálico.

${ }^{5}$ Felipe foi o único entrevistado que afirmou ter tido experiência de regência de sala de aula apenas durante as disciplinas de Estágio Supervisionado.
} 
V. 8 (3)

$364-382$

out-dez

2018

desmistificado na realidade, porque a gente vê que também não é TÃO monstruoso assim como eles pintam [...] continuo com esse pensamento que é importante, de que faz parte, de que vai me dar essa casca [...]

Assim como nos trechos destacados, todos os participantes realizaram escolhas lexicais relacionadas semanticamente ao medo e ao susto quando se referiram a crenças sobre a docência e o Estágio Supervisionado antes de terem suas próprias experiências. João utiliza os vocábulos engessado e complicado antecedidos pelo advérbio mais, denotando que ainda julga o Estágio como um processo regrado por questões administrativas obrigatórias (sua expectativa não foi totalmente distinta de sua experiência). A expressão não sei confere um menor comprometimento com o enunciado anterior, que pretende ser explicitado pelo próximo, esclarecendo que a representação citada foi construída por meio do que todo mundofala. A metáfora rádio corredor é utilizada para se referir aos comentários dos colegas que já cursaram a disciplina. Toda a sentença posterior apresenta vocábulos modalizadores não canônicos (ia: modo verbal condicional atenuante, tanto: asseverador do vocábulo acrescentar), no sentido de redução do comprometimento avaliativo de João, que é explicitado pelas escolhas do léxico acrescentar e a metáfora encher linguiça, sucedida novamente pela expressão modalizadora atenuante não sei. Essa representação do Estágio como algo não substancial é construída de maneira pouco comprometida, justificada pelo fato de que foram outros colegas que o fizeram, por suas experiências.

Felipe também utiliza o verbo assustar, antecedido pela expressão atenuante até um pouco, demonstrando baixo comprometimento. Preconceito é outra escolha lexical com a qual constrói sua própria representação, atenuando sua responsabilidade pela expressão a gente, incluindo-se, mas destacando não ser o único. O pensamento sobre o Estágio é desmistificado (uma construção de outrem que só pode ser confirmada ou refutada mediante experiência pessoal), vocábulo antecedido pela expressão um pouco, em sentido modalizador de atenuação. A escolha lexical monstruoso, constituinte da metáfora como eles pintam, reforça um conceito assustador ou de medo, palavra escolhida por Viviane para o mesmo processo (o estágio). Cabe ressaltar que monstruoso é novamente precedido do asseverador tão, que, aplicado assim, denota que, de alguma forma, o período do estágio ainda é considerado algo que se teme ${ }^{6}$.

\footnotetext{
${ }^{6}$ Viviane, Felipe, João e Helena ainda cursam disciplinas de estágio em 2018.1.
} 
A fala de Felipe é concluída com mais uma expressão metafórica (dar essa casca), representando a experiência durante o estágio como marcante e que trará uma espécie de proteção para sua identidade como profissional formado. Outra metáfora semelhante é acionada por Felipe em outro trecho: 'todas aquelas situações adversas que vão tete dando/ te encalejando né? mas de um jeito bom.' Felipe reconhece que há situações adversas que precisam ser vencidas. A metáfora da experiência como um calo, uma marca ou cicatriz denota o árduo trabalho do professor (sua batalha/luta), que ele considera positiva e essencial para sua formação.

Quando falam de suas próprias experiências, os entrevistados seguem fazendo avaliações do estágio relacionadas à afetividade:

Lucas: [...] Agora, com a sala de aula que é que realmente o curso deveria preparar/eu não digo nem prepara, DEVERIA preparar/ é complicado, porque a gente meio que cai de paraquedas, como três colegas que simplesmente ficaram desesperados [...]

Lucas critica a prioridade conferida aos princípios teóricos nas disciplinas de estágio, usando a modalização deôntica7 expressa por deveria preparar, com efeito de sentido explicado pela sentença seguinte (não digo nem prepara) e repetida com ênfase entonacional. A metáfora cai de paraquedas é dita por Lucas mais de uma vez em sua entrevista e também citada por Helena; na frase ora analisada, ela é precedida pela expressão meio que, denotando baixo comprometimento avaliativo. A sentença posterior retoma um alto comprometimento a partir do adjetivo desesperados, reforçando a ligação afetiva que Lucas e seus colegas possuem com a prática docente e o Estágio. Em um sentido semelhante, a metáfora ser jogado é também frequentemente referida, por outros entrevistados (Helena, Carlos e Felipe):

Carlos: [...] não existe um acompanhamento de fato DO PROFESSOR ORIENTADOR de estágio. A gente é meio que JOGADO na sala de aula, depois faz um relatório e apresenta[... ] precisa ser melhor redimensionado esse TIPO de estágio né? os objetivos QUE ELES querem e que a gente consequentemente quer alcançar[...] não sei por qual motivo, não vai in loco. [...]

\footnotetext{
${ }^{7}$ Como discutido no tópico 2, as modalidades epistêmica e deôntica serão abordadas neste artigo a partir dos princípios da Gramática da Linguística Sistêmico-Funcional (LSF) de Halliday, que é adotada por Fairclough $(2001,2003)$ na constituição teóricometodológica da Análise de Discurso Crítica.
} 
v. 8 (3)

$364-382$

out-dez

2018

aí, a gente se vira para procurar (uma escola)[...] então não houve CRITÉRIO de escolha, houve OPORTUNIDADES.

Felipe: [...]então não tem essa específica, não. QUE EU ACHO QUE DEVERIA TER[...]Que seja assim: DIDÁTICA DA LÍNGUA ESPANHOLA, para a gente poder TER essa disciplina em separado mesmo[...] que nos oriente a como lidar com a NOSSA DIDÁTICA, porque, tá! todos os professores, ne? têm a sua didática, mas que fosse ESPECÍFICO[...]por mais que a gente tenha essa orientação inicial, a gente é meio que jogado, MESMO [...]

Os estagiários constroem imagem de si como jogados, que precisam se virar durante esse período. Carlos é categórico ao afirmar não haver acompanhamento do professor orientador no momento em que a aula está sendo ministrada, apenas na produção de gêneros escritos: planejamento de aula e relatório. Carlos sugere que o estágio seja melhor redimensionado, considerando que não necessita ser modificado completamente e compreendendo as demandas da disciplina como algo personalizado na figura dos professores-orientadores (que ELES querem) e não algo institucionalizado. Aspecto semelhante é representado pela metáfora de Lucas: 'a gente FICA MUITO PRESO ao professor que ministra a disciplina[...]meio que lhe poda para dar aula do jeito que ele quer'.

Felipe apresenta a metáfora ser jogado, por não haver didática específica para a Língua Espanhola, construindo uma imagem de si como desorientado. Ele apresenta modalização epistêmica (eu acho) e verbo deôntico (dever ter) que se mostra sobremodalizado (FIORIN, 2008) em razão do tempo usado na conjugação verbal, denotando baixo comprometimento avaliativo em sua proposta. Consultando a estrutura curricular dos cursos das duas universidades, pudemos concluir que não há nenhuma disciplina voltada para a Didática de Línguas, como discutido na seção teórica como algo essencial nos cursos de Letras (DE JESUS, 2013). Os demais entrevistados corroboram a fala de Felipe de que conhecimentos de didática de línguas são uma lacuna na formação que eles almejam suprir durante o estágio docente, mas são frustrados.

Mediante as escolhas lexicais e metáforas presentes em todas as entrevistas, concluímos que elas constroem uma metáfora coletiva sobre como os estagiários representam a prática docente; e que, segundo suas falas, mantém-se após a conclusão do Estágio: a prática docente como um 'campo de batalha'. 
Lucas, por exemplo, ao falar da importância de ter escolhido estagiar em uma escola na qual já trabalhava, afirmou que isso facilitou implementar coisas novas, considerando que seria mais difícil se mudasse de local, pois seria necessário criar primeiro uma relação professoraluno. Essa relação foi expressa por Carlos distintamente, como uma relação aluno versus professor. O uso da expressão latina versus denota a representação de vários entrevistados, em seus discursos, sobre a prática docente como uma 'luta'. Além dessa representação, outros elementos lexicais e expressões revelam-se nas falas dos demais estagiários, nesse mesmo sentido:

Helena: [...] Vamos à luta! (sobre iniciar a carreira docente) Felipe: [...] que eu aprendi NA PRÁTICA é não enfrentar. Não adianta. Só piora; [...] dia a dia deles, do que eles enfrentam[...] João: [...] evitasse situações assim, de atrito com os alunos[...] Viviane: [...] o ponto máximo que a gente aguenta até pedir para o aluno que se retire ou chame a coordenação?

Luta, situações de atrito, enfrentar e aguentar são escolhas lexicais que marcam essa representação de embate na prática docente. Felipe, inclusive, atrela essa representação a uma construção social sobre o professor: "[...] parece que a gente tem que salvar o MUNDO [....]". Apenas esta última fala de Felipe possui o atenuador parece, enquanto as demais são avaliações categóricas de alto comprometimento avaliativo sobre a figura do professor.

O professor não pode estar despreparado para essa 'luta' ou correr risco de perdê-la, como esclarece Helena: [...] se chegar um professor [...] demonstrar insegurança ou demonstrar que ali ele é o estagiário e ele tá ali de/caiu de paraquedas, os alunos não vão deixar ele dar aula[...]. Mais uma vez, a construção metafórica caiu de paraquedas representa que o professor se encontra sozinho na sala de aula, tendo que lidar com todos os aspectos teóricos, metodológicos, psicológicos e sociais que envolvem a prática docente.

As escolhas lexicais dos entrevistados, como analisado até este ponto, apresentam o afeto como fator importante em vários aspectos do estágio: escolha da escola, adoção de teorias e métodos, qualidade das aulas etc. As falas a seguir reforçam esse ponto: 
V. 8 (3)

$364-382$

out-dez

2018

Lucas: os alunos/é como eu te disse, das três escolas, é a que eu mais tive apego afetivo, justamente por causa disso, a gente acabava CRIANDO um laço com os alunos [...]

João: foi a escola onde eu já estudei e dei aula também[...] então já tava em casa.

As falas são representativas de duas formas de relação afetiva explicitadas pelos entrevistados: afeto como instrumento didático e como mobilizador pessoal dos estagiários. João faz uso de uma metáfora que representa a escola como um local onde se sente bem, como sua casa. A maioria das expressões que indicam afeto nas avaliações dos estagiários são categóricas ou estão acompanhadas de modalizadores de asseveração/reforço (mais tive apego).

Indo além do aspecto afetividade, Helena relata e avalia como foi recebida pelos professores de uma das escolas na qual fez estágio de observação e constrói uma imagem do profissional docente:

Helena: [...]eu acho UM ABSURDO DOS PROFESSORES [...] eles perguntaram assim 'você tá fazendo isso?' 'isso o quê?' O estágio do espanhol, entendeu? 'você tá fazendo isso?' parecia que eu ia cometer um crime. Eu me senti assim, chega eu me assustei. Eu 'como assim?' 'minha filha, você é nova, vai procurar outra coisa para você' [...] só que é o seguinte, quando você escolhe a docência, você sabe muito bem o que tem pela frente e é mais uma questão de você ter uma ideologia, ter a construção de um papel social do que pelo dinheiro, porque ninguém vai ser professor e ficar rico, multimilionário. Isso aí, deixa para a política né? entre aspas (risos)[...]Eu fui fazer o estágio no Colégio X, e-e lá foi muito legal também, porém a gente encontrou uma barreira DA PROFESSORA, que no caso, ela meio que duvidou da nossa capacidade, por exemplo, de comandar a sala de aula e ela falou 'vocês vão voltar aqui e vão dar aula', como quem faz o desafio, entendeu? [...]a gente precisa ser corporativo e os alunos da própria docência não é corporativo e aí leva para a profissão e muitas vezes a gente não consegue mais conquistas por conta disso. Não somos corporativos, não somos. 
Essa é mais uma fala de Helena que mantém uma riqueza de escolhas lexicais para a construção de uma identidade docente, em um sentido que vai do real ao ideal. As modalizações epistêmicas (eu acho, meio que) são raras na fala dessa estagiária, que geralmente utiliza asseveradores e expressões categóricas em suas avaliações. A metáfora cometer um crime e encontrar uma barreira contribuem para a construção de uma imagem do corpo docente da escola onde estagiou como profissionais que desmotivam, assustam e são desarticulados (aqui ela utiliza o deôntico: a gente precisa ser coorporativo); além de não serem conscientes de seu papel social. Helena afirma que, quando se escolhe a docência, a pessoa sabe muito bem o que tem pela frente, mas desconsidera o fato relatado por outros entrevistados sobre a desistência de estudantes de Letras antes, durante e depois do estágio.

Quando Helena cita a importância da construção do papel social do professor, que precisa ter uma ideologia e que não vai ficar rico, milionário, ela demonstra comprometimento com os aspectos da docência que vão além da transposição didática ou da interação com os discentes, além de ironizar a corrupção governamental do país. Esse é um aspecto que pode ser relacionado à discussão sobre identidade profissional docente (TARDIF, 2005) e sobre o que Imbernón (2014, p. 14) chama de 'papel social do professor na contemporaneidade'. Helena se apropria de conceitos sociais que compõem sua identidade docente e a levam a uma reflexão crítica sobre o que é ser professor; aspecto importante para a ADC de Fairclough.

A imagem docente é construída de maneira distinta quando se trata do professor do estágio. Os estagiários relataram que há falta de acompanhamento in loco do/a orientador/a, que apenas auxilia no planejamento das aulas. A reflexão mais detalhada da figura do professor-orientador também é feita por Helena:

[...]muitas vezes, o professor da universidade não entendeu que é uma troca de saberes entre o professor e o aluno, porque, muitas vezes tem alunos de outras áreas que complementam o seu conhecimento; e isso não é válido? Isso é você ter humildade e saber, aí você vai aprender muito mais. Agora, o professor, ele se coloca num pedestal, o aluno não pode falar, o aluno não sabe, o aluno cala a boca, porque tem isso aqui. Eu tô estudando com uma professora NESSE SEMESTRE, que eu me tremo TODINHA, que eu não posso falar nada, 
v. 8 (3)

$364-382$

out-dez

2018

entendeu? Principalmente quando entra os debates de inclusão, principalmente quando entra os debates de-de realidade em sala de aula...TUDO ISSO eu posso falar com propriedade de CAUSA[...] E pra complementar, eu ainda faço a minha especialização em Psicopedagogia. Então, assim, eu vejo muita coisa de-de uma área que, enfim/ [...] eu acho que uma das soluções para esse problema é o seguinte, 'vai ser professor da Universidade? vou. Você já passou pelo ensino médio? Você já passou pelo Fundamental 2? Que aqui é fundamental 2 e ensino médio. 'Ah, passei' 'Não passei'/ porque o professor PRECISA ENTENDER COMO É QUE FUNCIONA. Tem professor aqui que nunca NEM DEU AULA, só fez o estágio, terminou sua faculdade e foi fazer as-as progressões verticais [...] ]esse professor não sabe da realidade, como tem muito professor que é MUITO BOM aqui, MARAVILHOSOS; porém, estão DEFASADOS em termos de REALIDADE. Então, por aí né? que anda a situação[...]

O/a orientador/a é uma figura docente na qual se inspira o formando; ainda que, no início de carreira, o licenciado trabalhe com um público diferente. Helena faz uma crítica, portanto, ao posicionamento de alguns professores da instituição, que não compartilham da visão de Academia como uma troca de saberes (a expressão muitas vezes tem função atenuadora dessa afirmação). A metáfora se coloca num pedestal denota a construção discursiva dessa imagem docente, reforçada pela expressão eu me tremo TODINHA; a escolha pelo vocábulo humildade também é relevante nessa construção. Ao defender esse ponto, Helena utiliza seus conhecimentos sobre Psicopedagogia e a experiência de sala de aula como relevantes para a discussão sobre ensino inclusivo, tema que afirma ter propriedade de causa, o que traz para a discussão o que Foucault (2006) designa de 'saber-poder'. Os saberes complementares ao curso de Letras e sua experiência são poderes acionados por Helena nessa discussão, enquanto acusa a professora de usar o seu lugar social de poder (professora universitária, com títulos, papel dominante) como forma de tolher a participação dos estagiários (formandos, papel social dominado). Cabe ressaltar que essa relação assimétrica de poder é natural e necessária na prática acadêmica, mas a estagiária faz uma crítica ao abuso desse poder, o que é prejudicial no processo formativo e, mais especificamente no que Celani $(2000,2004)$ trata 
sobre interação professor-aluno, aqui marcada pelo autoritarismo da docente e consequente silenciamento dos discentes. Pimenta e Lima (2004, p. 14) asseveram que "o Estágio torna-se possibilidade de formação contínua para os professores formadores", e isso é defendido com alto comprometimento avaliativo na fala de Helena (o professor PRECISA ENTENDER COMO É QUE FUNCIONA; MARAVILHOSOS; porém, estão DEFASADOS).

O discurso administrativo também foi enfatizado por todos os estagiários: a quantidade de textos que precisam conhecer antes de ir à sala de aula (dentre os citados estão os PCNs, o PPP e as normas da $\mathrm{ABNT}^{8}$ ) e que precisam preencher ou produzir (plano de aula, relatório de estágio, documentos para gestão e professor regente da escola).

Helena e Carlos destacam, ainda, que o método de avaliação do Estágio de Regência está aquém do imaginado por eles como objetivo da disciplina:

Helena: [...] Então, o quê que interessa? um relatório 100\% na ABNT?[...]

Carlos: [...]Então, nós TRABALHAMOS/é-é/ fazemos esse trabalho, voltado para a Licenciatura, pra docência, e no entanto, nos é-é/é pedido para a gente, no final do estágio, UMA MONOGRAFIA. [...]

Os estagiários criticam de maneira categórica que a avaliação da disciplina, que deveria priorizar a prática, acaba tendo foco na produção textual e na comprovação de assimilação de teorias, o que já é amplamente trabalhado ao longo do curso. Helena e Carlos defendem que a avaliação deveria ter maior valor atrelado à observação do professor da universidade da realização efetiva da aula (in loco), aspecto enfatizado por todos os entrevistados.

Sem dúvidas, a escolha lexical dos entrevistados foi fator mais destacado durante a análise, revelando construções representacionais e identificacionais como ideológicas. É incontestável que, diante das inúmeras possibilidades nos eixos sintagmático e paradigmático da língua, essas escolhas linguístico-discursivas dos atores sociais são relevantes em uma análise de discurso de perspectiva crítica, revelando, dentre outros aspectos, relações de poder e ideologia.

${ }^{8}$ PCN: Parâmetros Curriculares Nacionais; PPP: Projeto Político Pedagógico; ABNT: Associação Brasileira de Normas Técnicas. 
v. 8 (3)

$364-382$

out-dez

2018

\section{Conclusões}

Diante dos aspectos discutidos na análise, podemos concluir que uma abordagem crítica sobre discursos de estagiários de LetrasEspanhol possibilita um prisma que destaca questões merecedoras de mais atenção na formação desses futuros professores, além de impactar sobremaneira em sua carreira profissional. As falas deixaram claro que diversas crenças sobre a prática docente foram modificadas após a realização do Estágio Supervisionado, e que isso possibilitou, neles, tomada de decisão para sua atuação. Ressaltam, ainda, a incongruência entre teoria e prática perpassando toda a formação, não apenas em sua última fase, que é o Estágio, ocasionando dificuldades de transposição didática em razão do despreparo dos alunos.

É importante defender o Estágio, não apenas como um período de aplicação, mas de desenvolvimento profissional em diversos aspectos. O encontro entre o professor regente e o estagiário proporciona crescimento profissional a ambos; assim como ao orientador da universidade. A ênfase discursiva em aspectos afetivos também deve ser trabalhada em sua formação, que, de acordo com os estagiários, está calcada em aspectos formais do ensino de línguas. Isso pode suscitar uma formação crítico-reflexiva, proporcionando imersão em diversos contextos de docência.

Ressaltamos a importância de novos questionamentos a partir da análise das falas dos demais atores sociais implicados (professores orientadores do Estágio Supervisionado, professores regentes nas escolas e alunos da escola). Uma proposta interessante é a de uma pesquisa de natureza etnográfico-discursiva (MAGALHÃES, 2000), que se tem provado de grande valor na compreensão de diversas práticas sociais. Dessa forma, formar-se-ia um panorama mais amplo dessa temática.

\section{Referências}

BARROS, C.; COSTA, E.; GALVÃO, J. (org). Dez anos da "Lei do Espanhol" (2005-2015). Belo Horizonte: FALE/UFMG, 2016.

CELANI, M. A. A. A relevância da Linguística Aplicada na formula- ção de uma política educacional brasileira. In: FORTKAMP, M. B. M.; TOMITCH, L. M. B. (Orgs.). Aspectos da Linguística Aplicada: estudos em homenagem ao professor Hilário I. Bohn. Florianópolis: Insular, 2000. p. 17-32. 
C. Magalhães (Org.). A formação do professor como um profissional crítico: linguagem e reflexão. Campinas: Mercado de Letras, 2004. p. 37-56.

CERTEAU, M. A escrita da história. 2. ed. Rio de Janeiro: Forense Universitária, 2008.

COELHO, F. C. B. Construção identitária e(m)comportamentos na sala de aula: o agenciamento da palavra em dois grupos (um alemão e um brasileiro). Tese (Doutorado em Linguística) - Pontifícia Universidade Católica de Minas Gerais, Belo Horizonte, 2011.

DE JESUS, D. F. Didática de Línguas e Cultura Linguística do Colégio Dom José I. Tese. Universidade de Aveiro, Departamento de Educação, 2013.

ELLIS, R. The study of second language acquisition. Oxford: Oxford University Press, 1994 .

FAIRCLOUGH, N. Critical discourse analysis: the critical study of language. London:Longman, 1995. $\overline{166,2002}$. Language in New Capitalism. Discourse \& Society, v. 13, p. 163-

Discurso e mudança social. (tradução: Izabel Magalhães et al.) Brasília - DF: Editora Universidade de Brasília, 2001.

Analysing discourse: Textual analysis for social research. New York: Routledge, 2003.

FIORIN, J. L. Linguagem e interdisciplinaridade. Revista Alea, Rio de Janeiro, v. 10, n. 1, p. 29-53, jan./jun. 2008.

FOUCAULT, M. Estratégia, poder-saber. Rio de Janeiro. 2. ed. Forense Universitária, 2006.

GAUTHIER, C. et al. Por uma teoria da Pedagogia. Ijuí: Unijuí, 1998.

GIDDENS, A. As consequências da modernidade. Tradução de Raul Fiker. São Paulo: Editora UNESP, 1991.

GIMENEZ, T.; CRISTOVÃO, V. L. L. Derrubando paredes e construindo pontes: formação de professores de língua inglesa na atualidade. Revista Brasileira de Linguística Aplicada, Belo Horizonte, MG, v. 4, n. 2, p. 85-95, 2004.

IMBERNÓN, Francisco. Formação docente e profissional: formar-se para a mudança e a incerteza. São Paulo: Cortez, 2014.

MAGALHÃES, I. Eu e tu: a constituição do sujeito no discurso médico. Brasília: Thesaurus, 2000.

Teoria crítica do discurso e texto. Linguagem em (Dis)curso, v. 4, n. esp, p. 223-243, 2004.

MATENCIO, M. de L. M. Estudo da língua falada e aula de língua materna: uma abordagem processual da interação professor/alunos. Campinas, SP: Mercado de Letras, 2001. 
v. 8 (3)

$364-382$ out-dez 2018

MOREIRA, G. et al. (Org.). Reflexões e ações no ensino e aprendizagem de Espanhol/LE. Fortaleza: EdUECE, 2013.

PIMENTA, Selma G.; LIMA, Maria S. L. Estágio e docência. São Paulo: Cortez, 2004 .

PRATA, N. P. P. et al. (Org.). Espanhol em pauta: perspectivas teóricoanalíticas. Curitiba: Appris, 2017.

SCHLEE, M. B. Breve abordagem da categoria discursiva modalidade. Revista da Academia Brasileira de Filologia, V. IX, p. 157-169, 2011.

SCHNEWLY, B.; DOLZ, J. Os gêneros escolares - das práticas de linguagem aos objetos de ensino. Revista Brasileira de Educação, n. 11, p. 5-16, mai-ago, 1999.

TARDIF, M. Saberes docentes e formação profissional. Petrópolis: Vozes, 2005.

WODAK, R; MEYER, M. Critical Discourse Analysis: history, agenda, theory and methodology, 2009. 